\title{
Predictive genomic biomarkers for drug-induced nephrotoxicity in mice
}

\author{
Chiaki Kondo', Miwa Aoki², Emi Yamamoto', ${ }^{1,3}$, Yutaka Tonomura', Minoru Ikeda ${ }^{3}$, \\ Masako Kaneto ${ }^{1}$, Jyoji Yamate ${ }^{3}$, Mikinori Torii ${ }^{1}$ and Takeki Uehara ${ }^{1,3}$ \\ ${ }^{1}$ Drug Developmental Research Laboratories, Shionogi \& Co., Ltd., 3-1-1 Futaba-cho, \\ Toyonaka, Osaka 561-0825, Japan \\ 2Drug Discovery Research Laboratories, Shionogi \& Co., Ltd., 3-1-1 Futaba-cho, Toyonaka, Osaka 561-0825, Japan \\ ${ }^{3}$ Department of Veterinary Pathology, Graduate School of Agriculture and Biological Science, \\ Osaka Prefecture University, 1-58 Rinkuu Ourai Kita, Izumisano, Osaka 598-8531, Japan
}

(Received April 14, 2012; Accepted May 21, 2012)

\begin{abstract}
The present study aimed to establish candidate biomarker genes for the early detection of nephrotoxicity in mice, with a particular focus on nephrotoxicity caused by polyene macrolides. Comprehensive gene expression changes were evaluated using microarrays in a mouse model in which acute nephrotoxicity was induced by amphotericin B deoxycholate, trade name Fungizone. The upregulated genes identified through microarray analysis of kidney tissue of Fungizone-treated mice included several genes that have been reported as nephrotoxicity biomarkers in rats, and 14 genes were selected as candidate nephrotoxicity biomarkers. The usefulness of these genes as nephrotoxicity biomarkers in mice was evaluated further through expression profiling under several experimental conditions using real time RT-PCR. Expression of genes encoding kidney injury molecule 1, lipocalin 2, tissue inhibitor of metalloproteinase 1, and secreted phosphoprotein 1 was highly upregulated by Fungizone, nystatin, natamycin, amphotericin B methyl ester, and liposomal amphotericin B, and their area under the ROC curve values were more than 0.95 . These genes were more sensitive at detecting nephrotoxicity than traditional clinical chemistry and histopathology parameters. This study provides novel evidence that these nephrotoxicity biomarker genes identified are translatable to mice, and that they are useful for early and sensitive detection of nephrotoxicity.
\end{abstract}

Key words: Biomarker, Kidney, Mice, Nephrotoxicity, Toxicogenomics

\section{INTRODUCTION}

Polyene macrolides are clinically important antifungal agents used to treat systemic fungal infections. Amphotericin B (AMB) deoxycholate, also known as Fungizone $^{\circledR}$ (FGZ), is one of the most widely used polyene macrolide antifungals in human therapeutics. However, despite the effectiveness of polyene macrolides, clinical use of these drugs is restricted by their potential nephrotoxicity (Deray, 2002). Over the last a few decades, several candidate drugs designed to improve the effectiveness and minimize the nephrotoxicity of polyene macrolides have been synthesized and tested (Cybulska et al., 2000; Grzybowska et al., 1997; Keim et al., 1973; Reuhl et al., 1993). In addition, recent advances in drug delivery technology, such as the development of liposomes, emul- sions, and other systems, such as Ambisome ${ }^{\circledR}$, Amphocil $^{\circledR}$, and Abelcet ${ }^{\circledR}$, have reduced the nephrotoxicity of polyene macrolides (Clemons and Stevens, 2004; Dupont, 2002). However, since they contain AMB, these lipid formulations still exhibit a certain degree of nephrotoxicity (Leenders et al., 1998; Wingard et al., 2000). Selecting polyene macrolide candidates with reduced nephrotoxicity is therefore still a primary focus during the early stages of drug development.

Previously, we comprehensively characterized FGZinduced nephrotoxicity in mice (Tonomura et al., 2009). We found that FGZ-induced nephrotoxicity is marked by renal dysfunction, including a reduction in plasma filtration and an increase in urinary lactate dehydrogenase activity accompanied by renal tubular damage. Histopathologically, we found that tubular necrosis in the

Correspondence: Takeki Uehara (E-mail: takeki.uehara@shionogi.co.jp) 
thick ascending limb of Henle's loop is the main characteristic of FGZ nephrotoxicity in mice.

Toxicogenomics is an interdisciplinary research field that combines this DNA microarray-based molecular technology with conventional toxicology, and has been used as a universal tool to elucidate the molecular changes caused by toxic substances in several organ systems (Guengerich and MacDonald, 2007; Hayes and Bradfield, 2005). By applying a toxicogenomic approach, researchers can determine how gene expression responses to exposure to toxic substances are linked to toxic outcome, a process called phenotypic anchoring (Paules, 2003). Toxicogenomics can also be used to identify molecular targets and biomarker genes, and has been used to investigate hepatotoxicity (Harrill et al., 2009; Heinloth et al., 2004; Hirode et al., 2009; Kiyosawa et al., 2007; Uehara et al., 2008, 2011; Low et al., 2011), nephrotoxicity (Huang et al., 2001; Kharasch et al., 2006; Kondo et al., 2009; Luhe et al., 2003; Ozaki et al., 2010), and cardiotoxicity (Mori et al., 2010). A large number of toxicogenomic studies have focused on the nephrotoxicity of various prototypical compounds in rats. Along these lines, we previously characterized the changes in gene expression resulting from exposure to 33 nephrotoxicants and 8 non-nephrotoxicants in order to elucidate time- and dose-dependent global gene expression changes associated with renal tubular injury in rats. We identified 92 candidate biomarker genes and constructed a robust classification model for the concurrent diagnosis of renal tubular injury in rats (Kondo et al., 2009). The classification model consisted of several well-known biomarkers, such as kidney injury molecule 1 (Kiml), lipocalin 2 (Lcn2), secreted phosphoprotein 1 (Spp1), tissue inhibitor of metalloproteinase 1 (Timp1), and several other biomarker candidates.

There are several recent reports focusing on the new biomarkers of nephrotoxicity in predicting and monitoring early or acute nephrotoxicity. Recently, the Predictive Safety Testing Consortium's (PSTC) Nephrotoxicity Working Group published a report concerning the qualification of seven urinary nephrotoxic biomarkers, including total protein, albumin, kidney injury molecule-1, clusterin, $\beta 2$-microglobulin, cystatin $\mathrm{C}$, and trefoil factor 3 , for limited use in nonclinical and clinical drug development to help guide safety assessments (Dieterle et al., 2010). Although these biomarkers are useful for monitoring of rat nephrotoxicity, data supporting usefulness for monitoring mouse nephrotoxicity is limited. Additionally, despite the usefulness of toxicogenomic approaches for detecting nephrotoxicity associated with various drugs, the amount of information available regarding nephrotoxicity biomar- ker genes in mice is quite limited compared to rats. This is of critical concern because mice are one of the most commonly used experimental animals for assessing the efficacy and toxicity of candidates during the early stages of drug development. Therefore, it is absolutely imperative that nephrotoxic biomarkers in mice be identified, and that the usefulness of these genes as surrogate and/or predictive biomarkers of nephrotoxicity be evaluated.

The hypothesis we investigated in the present study is that nephrotoxic biomarker genes in rats are applicable to the detection of nephrotoxicity in mice. We utilized a toxicogenomic approach to identify candidate biomarker genes in mice. First, comprehensive gene expression changes were characterized in mouse kidney following a single nephrotoxic dose of FGZ. Several genes that have been reported as biomarkers in rats were identified as candidate biomarkers in mice based on changes in expression following treatment with FGZ. Changes in the expression of these genes were confirmed using quantitative real-time RT-PCR. We also evaluated the usefulness of the candidate biomarkers based on data for various other nephrotoxic and non-nephrotoxic compounds. Furthermore, in situ hybridization analysis confirmed increased expressions of Kim1, Lcn2, and Timp1 mRNA at the thin segment of Henle's loop in the FGZ-treated kidneys. Expression of the protein product of Sppl was confirmed by immunohistochemistry. The genes we identified in the present study are suitable for the detection of nephrotoxicity in mice and are useful translational biomarkers of nephrotoxicity in rodents.

\section{MATERIALS AND METHODS}

\section{Chemicals}

Amphotericin B deoxycholate (Fungizone ${ }^{\circledR}$, FGZ; Bristol-Myers Squibb, NY, USA), liposomal amphotericin B (AmBisome ${ }^{\circledR}$, L-AMB; Dainippon Sumitomo Pharma, Osaka, Japan), and amphotericin B methyl ester (AME; Karykion Inc., Princeton, NJ, USA) were dissolved in 5\% glucose solution (Otsuka Pharmaceutical Factory, Tokushima, Japan) prior to use. Nystatin (NYS), natamycin (NMC), and candicidin (CDD) were purchased from United States Pharmacopeia (USP; Rockville, MD, USA). These compounds were dissolved in physiological saline solution (Otsuka Pharmaceutical Factory) containing 5\% DMSO (Sigma, St Louis, MO, USA). Cephalothin (CET; Sigma) and cefepime (CFPM; USP) were dissolved in physiological saline solution. Ceftazidime (CAZ) and piperacilin (PIPC) were dissolved in 3.5\% sodium bicarbonate solution (MEYLON Injection 7\%; Otsuka Pharmaceutical Factory; diluted with distilled 
Nephrotoxicity biomarkers in mice

water). The choice of vehicle for the dosing solutions and the methods for preparation of compounds were selected based on the dosing formula in clinical use or compound solubility. Dosing solutions were used soon after preparation. All other chemicals used in this study were of the highest purity available.

\section{Animals and housing conditions}

Male Jcl:ICR mice were purchased from CLEA Japan, Inc. (Tokyo, Japan), and were acclimated for 1 week. All animals were housed with a 12-hr lighting period (light on 8:00-20:00) and were allowed free access to food (autoclaved CE-2, CLEA Japan, Inc.) and water (sterilized city water). The animals were 5 weeks old at the initiation of drug administration.

\section{Experimental design}

The first day of administration was designated as Day 1 . In experiment (Exp.) 1, mice ( $\mathrm{n}=5$ /group) were intravenously treated with FGZ (2 or $4 \mathrm{mg} / \mathrm{kg}$ ) or vehicle alone at a dose volume of $20 \mathrm{ml} / \mathrm{kg}$ and sacrificed $24 \mathrm{hr}$ later. In Exp. 2, mice ( $\mathrm{n}=4$ /group) were intravenously treated with NYS (2.5 or $5 \mathrm{mg} / \mathrm{kg}$ ), NMC (25 or $50 \mathrm{mg} / \mathrm{kg}$ ), CDD (1.5 or $3 \mathrm{mg} / \mathrm{kg})$, CET (1,000 mg/kg), CFPM (1,000 mg/kg), CAZ (1,000 mg/kg), PIPC (1,000 mg/kg), or vehicle alone at a dose volume of $10 \mathrm{ml} / \mathrm{kg}$. All animals were euthanized $24 \mathrm{hr}$ after dosing. In Exp. 3, mice ( $n=4$ /group) were intravenously treated with L-AMB $(50,100$, or $200 \mathrm{mg} / \mathrm{kg}), \mathrm{AME}$ (25 or $50 \mathrm{mg} / \mathrm{kg}$ ), or vehicle alone at a dose volume of $20 \mathrm{ml} / \mathrm{kg}$ and euthanized $24 \mathrm{hr}$ later. In Exp. 4, mice ( $\mathrm{n}=10$ /group) were intravenously treated once a day with FGZ ( $2 \mathrm{mg} / \mathrm{kg} /$ day) or vehicle alone at a dosing volume of $20 \mathrm{ml} / \mathrm{kg} /$ day for 1 week. All animals were euthanized $24 \mathrm{hr}$ after the last dosing. All experimental procedures were conducted after the study was approved by the Institutional Animal Care and Use Committee in our facility.

\section{Blood chemistry measurements}

Blood samples were obtained under ether-anesthesia from the vena cava using heparinized syringes, and then animals were euthanized by exsanguination by cutting both the abdominal aorta and vena cava. Plasma samples were obtained by centrifuging blood at $1,500 \times g$ for $15 \mathrm{~min}$ at $4^{\circ} \mathrm{C}$. Levels of plasma urea nitrogen (UN) and creatinine were measured using an automatic analyzer 7180 (Hitachi High-Technologies Co., Tokyo, Japan) according to the manufacturer's instructions.

\section{Pathological examination}

After blood sample were collected, the right kidney was obtained for light microscopic examination. Kidneys were fixed in 10\% neutral buffered formalin, processed routinely, and embedded in paraffin. Paraffin sections were stained with hematoxylin and eosin (H\&E) for microscopy.

\section{RNA extraction}

For gene expression analysis, the left kidney was removed and stored at $-80^{\circ} \mathrm{C}$ in $\mathrm{RNAlater}^{\circledR}$ (Ambion, Austin, TX, USA) until use. Samples were disrupted and homogenized in QIAzol Lysis Reagent with TissueLyser (Qiagen, Valencia, CA, USA), and total RNA was extracted using an RNeasy ${ }^{\circledR}$ Mini kit (Qiagen). The subsequent steps were performed according to the manufacturer's instructions. The concentration and quality of RNA were assessed using a NanoDrop ND1000 spectrophotometer (Labtech International, East Sussex, UK) and a 2100 Bioanalyzer (Agilent Technologies, Santa Clara, CA, USA).

\section{Microarray analysis}

Microarray analysis was performed on samples of kidneys obtained in Exp. 1. The procedure was conducted basically according to the manufacturer's instructions using One-Cycle Target Labeling and Control Reagents (Affymetrix, Santa Clara, CA, USA) for cDNA synthesis and purification and synthesis of biotin-labeled cRNA. In addition, $10 \mu \mathrm{g}$ of fragmented cRNA was hybridized to a Mouse Genome 430A 2.0 Array (Affymetrix) for $17 \mathrm{hr}$ at $45^{\circ} \mathrm{C}$ at $60 \mathrm{rpm}$. The array was washed and stained with streptavidin-phycoerythrin using a Fluidics Station 450 (Affymetrix). Digital images were obtained using a Gene Array Scanner GCS3000 7G (Affymetrix) and analyzed with Microarray Analysis Suite 5.0 (MAS; Affymetrix).

\section{Microarray data analysis}

Microarray data obtained from high-dose-treated and control groups were used for selection of genes for which expression had significantly changed in response to treatment. First, microarray data were imported into Spotfire ${ }^{\circledR}$ DecisionSite for Functional Genomics (Spotfire, Göteborg, Sweden), and all signal intensities for each chip were normalized by the average value of all proves. Following statistical filtering between two groups using a Student's $t$ test $(P<0.05)$, probes upregulated more than 2 -fold or downregulated to less than 0.5 compared to the control were selected as significantly changed genes. In this step, the Affymetrix Detection Call algorithm was also used and the following probe sets were eliminated: probes showing an absent call in all animals of the FGZtreated group for selecting upregulated genes, and probes 
showing an absent call in all control animals for downregulated genes. To enhance the reliability of the selected genes identified with the microarray-based approach, probes with expressed sequence tags (ESTs) and/or Affymetrix's low grade annotation (grade E) were eliminated from further analysis. Finally, a total of 440 probes (358 upregulated and 82 downregulated) were selected as FGZ-responsive genes.

\section{Gene ontology (GO) analysis}

GO analysis of the FGZ-responsive genes was performed using the DAVID Functional Annotation tool (Database for Annotation, Visualization, and Integrated Discovery; http://david.abcc.ncifcrf.gov/). A level 5 analysis was adopted for the term of the GO biological process (threshold count: $>20$ ). A corrected $P$-value (Benjamini method) less than 0.01 was considered statistically significant.

\section{Quantitative RT-PCR}

The level of expression of the following genes was determined using one-step quantitative real-time PCR: Lcn2, Kim1, Timp1, Spp1, clusterin (Clu), vimentin (Vim), antigen identified by monoclonal antibody Ki 67 (Mki67), keratin 8 (Krt8), keratin 18 (Krt18), keratin 19 (Krt19), fibrinogen, gamma polypeptide $(F g g)$, fibrinogen, alpha polypeptide $(F g a)$, ceruloplasmin $(C p)$, and alpha-2-macroglobulin $(A 2 m)$. Total RNA $(0.4 \mu \mathrm{g})$ was used as the template, and TaqMan Gene Expression Assays (for Lcn2, assay ID: Mm01324472_g1; Havcr1 (Kim1), Mm00506686_m1; Clu, Mm00442773_ m1; Vim, Mm00449201_m1; Timp1, Mm01341361_ m1; Spp1, Mm00436767_m1; Mki67, Mm01278616_m1; Krt8, Mm01278616_m1; Krt18, Mm01601706_g1; Krt19, Mm00492980_m1; Fgg, Mm00513575_m1; Fga, Mm00802584_m1; Cp, Mm00432654_m1; A2m, Mm00558642_m1) or TaqMan Endogenous Controls (Gapdh, predesigned assay reagent supplied by ABI, Applied Biosystems, Foster City, CA, USA) were employed as gene-specific probe and primer sets. Quantitative RT-PCR was performed using a QuantiTect ${ }^{\mathrm{TM}}$ Probe RT-PCR kit (Qiagen), and transcript levels were quantitated with an ABI PRISM 7500 Fast System (Applied Biosystems) according to the manufacturer's instructions. Reverse transcription and amplification conditions were set as follows: $50^{\circ} \mathrm{C}$ for $30 \mathrm{~min}, 95^{\circ} \mathrm{C}$ for $15 \mathrm{~min}$, followed by 40 cycles at $95^{\circ} \mathrm{C}$ for $15 \mathrm{sec}$ and $60^{\circ} \mathrm{C}$ for $1 \mathrm{~min}$. The resulting cycle threshold $(\mathrm{Ct})$ value was processed based on the comparative $\mathrm{Ct}$ method, where Gapdh was used as an endogenous reference gene to normalize the expression level of target genes.

\section{In situ hybridization}

The procedure for in situ hybridization was performed using the Ventana XT System Discovery (with reagents from Ventana Medical Systems as part of the ISH assay, Ventana Medical Systems, Inc., Tucson, AZ, USA). Briefly, riboprobes were prepared from Kim1, Lcn2 or Timp1 cDNA fragments (GenBank database accession number NM_134248, NM_008491 or NM_001044384, respectively) by PCR amplification using primers as follows: Kim1 (5' -ggcactgtggattcttatgt-3', 5' -atgtagtgggttctggtttg-3'), Lcn2 (5'-tcaactcagaacttgatccc-3', 5'-agaagatgatgttgtcgtcc-3'), Timp1 (5' -ctggcatcctcttgttgcta-3', 5'-agggatctccaggtgcacaa-3'). PCR products were subcloned in pCR ${ }^{\circledR}$ II-TOPO ${ }^{\circledR}$ vector (Invitrogen, Carlsbad, CA, USA). The templates were linearized with BamHI (antisense probe) or Xho I (sense probe), and RNA probes were synthesized and labeled with T7 (antisense) or Sp6 (sense) RNA polymerase respectively in the presence of digoxigenin (DIG)-labeled UTP (DIG Labeling Kit; Roche Molecular Biochemicals, Indianapolis, IN, USA) according to manufacturer's recommendations.

For in situ hybridization and immunohistochemistry, the kidneys obtained from animals were used as described below. After the treatment with FGZ (4 mg/ $\mathrm{kg}$ ) or vehicle alone for $24 \mathrm{hr}$, mice were flushed with $0.1 \mathrm{M}$ phosphatebuffered saline (PBS, $\mathrm{pH}$ 7.4) followed by perfusion with $4 \%$ paraformaldehyde in PBS under the anesthesia. Kidney tissues were dissected and immersed in the same fixative overnight at $4^{\circ} \mathrm{C}$ and dehydrated by a diluted alcohol followed by xylene. The preparations were then passed into paraffin at $56^{\circ} \mathrm{C}$, and transversal sections (4- $\mu \mathrm{m}$ thick) were mounted on slides. After deparaffinization, the sections were incubated with Riboprep for $8 \mathrm{~min}$ at $37^{\circ} \mathrm{C}$, and treated with RiboClear for $8 \mathrm{~min}$ at $37^{\circ} \mathrm{C}$. Protein digestion was performed with Protease 2 ( 0.1 units $/ \mathrm{ml}$ ) for $24 \mathrm{~min}$ for Kim $1 \mathrm{mRNA}$ detection, for $20 \mathrm{~min}$ for Lch $2 \mathrm{mRNA}$ detection, or for $16 \mathrm{~min}$ for Timp $1 \mathrm{mRNA}$ detection at $37^{\circ} \mathrm{C}$, respectively. This was followed by incubation with the specific $250 \mathrm{ng} / \mathrm{ml} \mathrm{DIG}-$ labeled probes for $16 \mathrm{hr}$ at $65^{\circ} \mathrm{C}$. Detection was performed with DAB Map ${ }^{\mathrm{TM}}$ Kit and accessory reagents. The slides were washed with stringency washed, followed by post fixed with RibFix for $20 \mathrm{~min}$ at $37^{\circ} \mathrm{C}$ and incubated with $500 \mathrm{ng} / \mathrm{ml}$ Anti-Digoxigenin (Roche Applied Science, Indianapolis, IN, USA) for $48 \mathrm{~min}$ at $37^{\circ} \mathrm{C}$ followed by $750 \mathrm{ng} / \mathrm{ml}$ biotinylated anti-sheep $\operatorname{IgG}(\mathrm{H}+\mathrm{L})$ for $28 \mathrm{~min}$ at $37^{\circ} \mathrm{C}$, and subsequent substrate treatment for $60 \mathrm{~min}$ at $37^{\circ} \mathrm{C}$. The sections were counterstained with $1 \%$ methyl green dye, dehydrated, and mounted. 
Nephrotoxicity biomarkers in mice

\section{Immunohistochemistry}

Immunohistochemical staining for the protein product of Spp 1, osteopontin, was performed as follows. The prepared slides of kidney sections were deparaffinized and rehydrated with graded alcohol. Antigen retrieval was performed using a microwave oven $(5 \mathrm{~min}$, citrate buffer of $\mathrm{pH}$ 6.0). After incubating in methanol containing $0.3 \% \mathrm{H}_{2} \mathrm{O}_{2}$, the sections were treated with $5 \%$ normal rabbit serum for $30 \mathrm{~min}$, followed by incubation with $1.7 \mu \mathrm{g} / \mathrm{ml}$ anti-mouse osteopontin (R\&D System, Inc., Minneapolis, MN, USA) in PBS containing $0.1 \%$ normal rabbit serum for $1 \mathrm{hr}$ at room temperature. Following washing with PBS, the sections were incubated with biotinylated secondary antibody for $30 \mathrm{~min}$. After washing with PBS, they were incubated with VECTASTAIN Elite ABC Reagent (Vector Laboratories, Inc.), and then the peroxidase activity was visualized by incubation with DAB substrate (Roche).

\section{Statistical analysis}

GraphPad Prism (GraphPad Software Inc., San Diego, CA, USA) was used for statistical analyses. Statistical significance of differences was determined using
Welch's t-test for comparisons involving two groups and Dunnett's multiple comparison test was used for comparisons involving three or more groups. Receiver operating characteristic (ROC) curve analysis was performed to assess the prediction performance of each biomarker gene and ROC curves were plotted using a nonparametric method.

\section{RESULTS}

\section{Classical phenotypic toxicology data}

Histopathological findings and plasma nephrotoxicity biomarker levels are summarized in Table 1. In the 2 and $4 \mathrm{mg} / \mathrm{kg}$ single-dose FGZ-treated groups (Exp. 1), minimal to moderate dose-dependent tubular necrosis was observed in the thin segment of Henle's loop in the renal medulla (Fig. 1). Following daily administration of $2 \mathrm{mg} / \mathrm{kg}$ of FGZ for 1 week (Exp. 4), regenerative lesions reflecting tubular injury became apparent (Fig. 1), whereas minimal to moderate tubular necrosis was still observed in the thin segment of Henle's loop. Tubular necrosis of Henle's loop in the renal medulla was also observed in the kidneys of NYS- and NMC-treated mice in Exp. 2, and

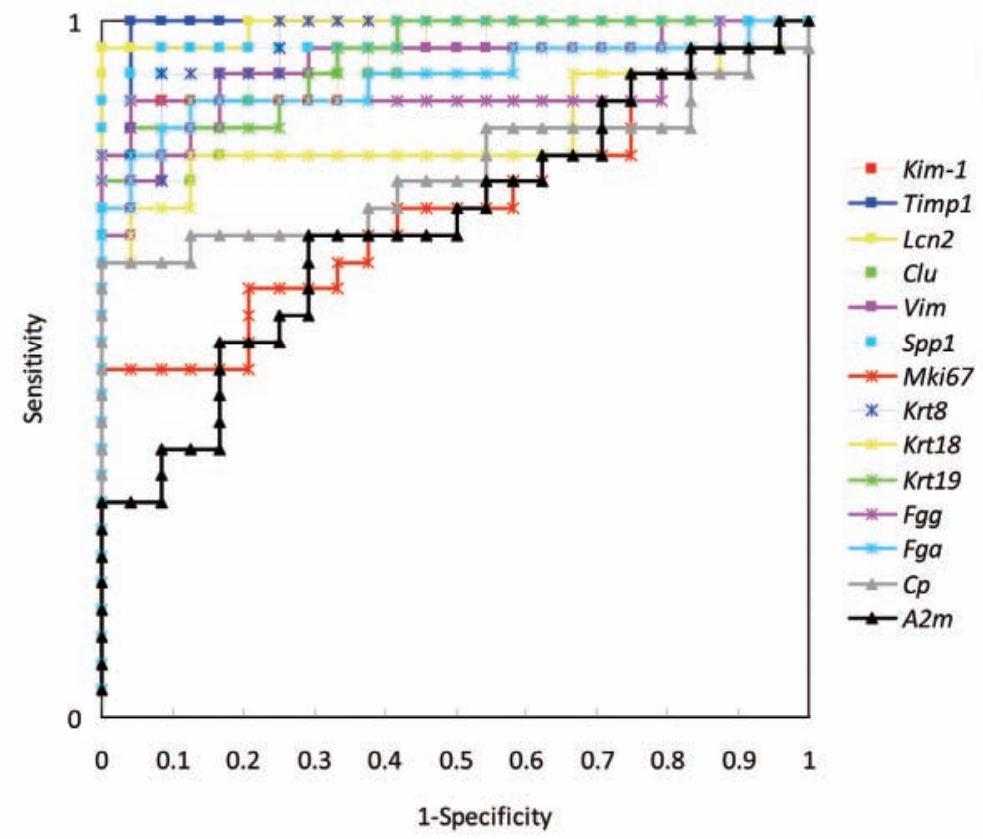

\begin{tabular}{|c|c|c|c|c|}
\hline Gene & AUC & $\begin{array}{c}\text { Cut-off } \\
\text { value }\end{array}$ & $\begin{array}{c}\text { Specificity } \\
(\%)\end{array}$ & $\begin{array}{c}\text { Sensitivity } \\
(\%)\end{array}$ \\
\hline Timp1 & 0.99 & 0.509 & 95.8 & 100 \\
\hline Lcn2 & 0.99 & 1.550 & 100 & 96.2 \\
\hline Spp1 & 0.98 & 0.646 & 95.8 & 92.3 \\
\hline Krt8 & 0.96 & 0.171 & 91.7 & 92.3 \\
\hline Kim1 & 0.96 & 2.282 & 100 & 88.5 \\
\hline Krt19 & 0.95 & 0.668 & 95.8 & 84.6 \\
\hline Clu & 0.94 & 0.228 & 83.3 & 88.5 \\
\hline Vim & 0.93 & 0.230 & 83.3 & 92.3 \\
\hline Fga & 0.92 & 0.355 & 87.5 & 88.5 \\
\hline Fgg & 0.90 & 0.369 & 95.8 & 88.5 \\
\hline Krt18 & 0.84 & 0.499 & 87.5 & 80.8 \\
\hline Cp & 0.79 & 0.762 & 87.5 & 69.2 \\
\hline Mki67 & 0.73 & 0.331 & 79.2 & 61.5 \\
\hline A2m & 0.71 & 0.317 & 70.8 & 69.2 \\
\hline & & & & \\
\hline
\end{tabular}

Fig. 1. Light micrograph of kidneys with H\&E staining. (A) Renal medulla of a control mouse treated with vehicle alone in a single-dose experiment. (B) Renal medulla of a mouse treated with $4 \mathrm{mg} / \mathrm{kg}$ of Fungizone in a single-dose experiment. Arrowheads indicate tubular epithelial cell necrosis. (C) Renal cortex of a control mouse treated with vehicle alone in a repeateddose experiment. (D) Renal cortex of a mouse treated with $2 \mathrm{mg} / \mathrm{kg} /$ day of Fungizone in a repeated-dose experiment. Arrow indicates regeneration of the proximal tubules. Magnification: $\times 200$. 
C. Kondo et al.

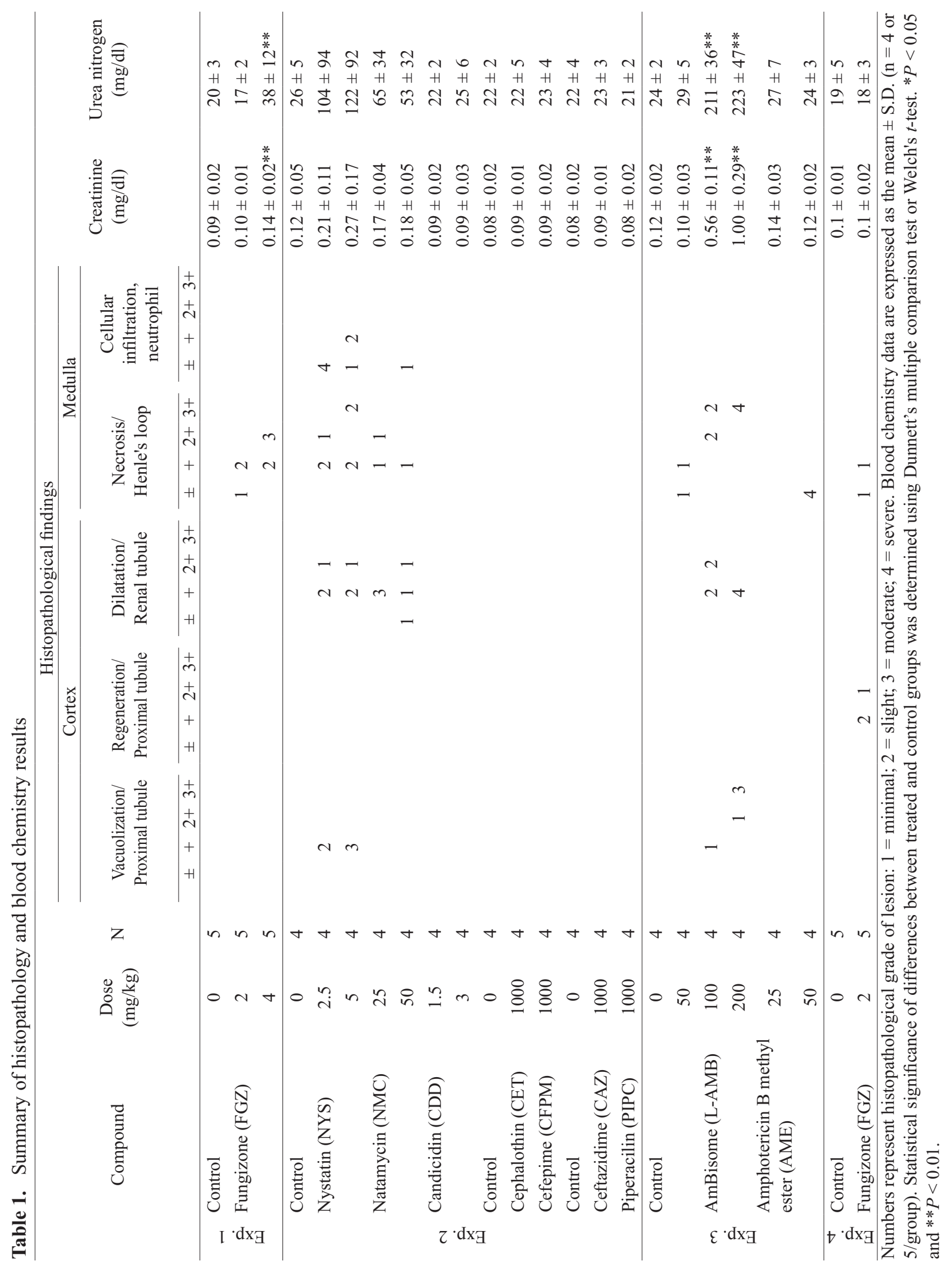

Vol. 37 No. 4 
Nephrotoxicity biomarkers in mice

in the kidneys of L-AMB- and AME-treated mice in the Exp. 3. Whereas moderate to severe tubular necrosis was observed in the kidneys of 100 and $200 \mathrm{mg} / \mathrm{kg}$ L-AMBtreated mice, only minimal to slight tubular necrosis was observed at the lowest dose, $50 \mathrm{mg} / \mathrm{kg}$. In the AME-treated groups, no abnormal changes were observed at a dose of $25 \mathrm{mg} / \mathrm{kg}$, but minimal tubular necrosis was observed at a dose of $50 \mathrm{mg} / \mathrm{kg}$. In some cases, necrotic changes were accompanied by neutrophilic inflammation in the connective tissue of the medulla. In the renal cortex, proximal tubular dilatation was observed in the kidneys of NYS- and NMC-treated animals in Exp. 2 and the kidneys of L-AMB-treated animals in Exp. 3. In the kidneys of NYS- and L-AMB-treated mice, degenerative vacuolar changes were observed in the cortical proximal tubule.

Increased levels of plasma UN and creatinine accompanied by renal tubular injury were also observed in groups treated with these nephrotoxic compounds; however, the changes were statistically significant only in $4 \mathrm{mg} / \mathrm{kg} \mathrm{FGZ}$ - and 100 and $200 \mathrm{mg} / \mathrm{kg}$ L-AMB-treated groups. In contrast, no renal histopathological lesions or elevations in clinical parameters were found in the groups treated with following compounds: CDD, CET, CFPM, CAZ, and PIPC. Thus, these compounds were considered non-nephrotoxic under the current experimental conditions.

\section{FGZ-induced nephrotoxicity responsive genes}

In order to examine comprehensive gene expression changes related to nephrotoxicity induced by polyene macrolides, kidney samples showing slight to moderate renal tubular necrosis obtained from mice treated with $4 \mathrm{mg} / \mathrm{kg}$ of FGZ were analyzed by microarray. Following statistical filtering for gene selection, 358 probes (350 genes) were identified as upregulated genes (Supplemental Table 1A), and 82 probes (79 genes) were identified as downregulated genes (Supplemental Table 1B).

A GO analysis was performed to obtain functional annotations for the upregulated and downregulated genes identified by microarray analysis. The GO analysis indicated that 39 categories of biological processes were modulated by the upregulated genes (level 5, $P<0.01$ ). Functional annotation indicated that the upregulated genes are involved in cell cycle regulation, inflammatory responses, cell death, and DNA metabolism, which is consistent with our previously reported findings regarding rat nephrotoxicity (Kondo et al., 2009) (Supplemental Table 2A). The downregulated genes were found to be involved in several metabolic processes that are considered to reflect renal tubular malfunction (Supplemental Table 2B).

\section{Selection of candidate biomarker genes}

Among the genes differentially expressed in the kidneys of FGZ-treated mice, upregulated genes were chosen for further evaluation because upregulation may directly reflect tissue injury associated with nephrotoxicity. Furthermore, among the upregulated genes, 14 were selected as candidate biomarkers based upon their putative biological function and available information regarding their use as biomarkers in rats (Kondo et al., 2009; Uehara et al., 2007): Lcn2, Havcr1, Timp1, Clu, Fgg, Fga, A2m, Krt18, Krt19, Spp1, Mki67, Vim, Cp, and Krt8. The expression of these genes in 2 and $4 \mathrm{mg} / \mathrm{kg}$ FGZ-treated mice was then examined using quantitative RT-PCR analysis of the same RNA samples that were used for the microarray experiment. Changes in the expression of the 14 candidate biomarker genes were represented as $\Delta \Delta \mathrm{Ct}$. In addition, the level of expression of these genes was measured in the $2 \mathrm{mg} / \mathrm{kg}$ FGZ-treated group to confirm the dosedependency of gene expression changes. As shown in Tables 2 and 3, quantitative RT-PCR analysis confirmed that the 14 candidate biomarker genes are upregulated in a dose dependent manner in response to FGZ-treatment, and a high degree of concordance was observed between the microarray and RT-PCR data.

\section{ROC analysis}

Experiment 2 involved the use of several different classes of nephrotoxic and non-nephrotoxic antibiotics for the purpose of further gene selection based on the results of ROC analyses. The expression of the 14 candidate biomarker genes in the mice in Exp. 2 was measured using quantitative RT-PCR (Table 3). For ROC analysis, the NYS- and NMC-treated groups were defined as nephrotoxicity positive, and the remaining groups (CDD-, CET-, CFPM-, CAZ-, and PIPC-treated mice), which demonstrated no phenotypic evidence of nephrotoxicity, were defined as nephrotoxicity negative. ROC curves were plotted on the basis of the set of sensitivity and 1-specificity values (Fig. 2). The area under the ROC curve (AUC) values for the 14 candidate biomarker genes ranged between 0.708 and 0.992 . The five topranked genes (Kim1, Lcn2, Timp1, Spp1, and Krt8) each had an AUC value greater than 0.95 and were selected for further evaluation.

\section{Eternal validation in single dose conditions}

In the next study (Exp. 3), we also examined the effect of two AMB-derived products, L-AMB and AME, on expression of the five top-ranked genes selected using ROC analysis. L-AMB is liposomal formulation of AMB, and AME is a water-soluble AMB derivative with greatly 
Table 2. Comparison of DNA microarray and quantitative RT-PCR measurements for 14 selected genes expressed in the kidneys of mice treated with $4 \mathrm{mg} / \mathrm{kg}$ of FGZ

\begin{tabular}{|c|c|c|c|c|c|}
\hline \multirow[b]{2}{*}{ Probe ID } & \multirow[b]{2}{*}{ Accession No. } & \multirow[b]{2}{*}{ Gene symbol } & \multirow[b]{2}{*}{ Gene title } & \multicolumn{2}{|c|}{ Gene expression } \\
\hline & & & & Microarray & RT-PCR \\
\hline 1450364_a_at & NM_134248 & Kim1 & kidney injury molecule 1 & 4.42 & $6.88 \pm 0.71$ \\
\hline 1460227_at & NM_001044384 & Timpl & tissue inhibitor of metalloproteinase 1 & 3.86 & $5.79 \pm 0.04$ \\
\hline 1427747_a_at & NM_008491 & $\operatorname{Lcn} 2$ & lipocalin 2 & 5.27 & $6.00 \pm 0.49$ \\
\hline 1418626_a_at & NM_013492 & $\mathrm{Clu}$ & clusterin & 3.31 & $3.28 \pm 0.35$ \\
\hline 1450641_at & NM_011701 & $\operatorname{Vim}$ & vimentin & 1.20 & $1.45 \pm 0.17$ \\
\hline 1449254_at & NM_009263 & Sppl & secreted phosphoprotein 1 & 1.31 & $4.16 \pm 0.16$ \\
\hline 1426817_at & NM_001081117 & Mki67 & antigen identified by monoclonal antibody Ki 67 & 1.23 & $1.44 \pm 0.12$ \\
\hline 1435989_x_at & NM_031170 & Krt8 & keratin 8 & 1.02 & $1.34 \pm 0.19$ \\
\hline 1448169_at & NM_010664 & $K r t 18$ & keratin 18 & 1.95 & $2.42 \pm 0.09$ \\
\hline 1417156_at & NM_008471 & Krt19 & keratin 19 & 1.53 & $2.12 \pm 0.12$ \\
\hline 1416025_at & NM_133862 & $F g g$ & fibrinogen, gamma polypeptide & 3.25 & $3.35 \pm 1.12$ \\
\hline 1424279_at & NM_001111048 & Fga & fibrinogen, alpha polypeptide & 2.86 & $2.69 \pm 0.67$ \\
\hline 1417496_at & NM_001042611 & $C p$ & ceruloplasmin & 1.16 & $1.51 \pm 0.17$ \\
\hline 1434719_at & NM_175628 & $A 2 m$ & alpha-2-macroglobulin & 2.31 & $3.25 \pm 0.87$ \\
\hline
\end{tabular}

Gene expression levels are shown as the $\log 2$ ratio of treated to control animals. For quantitative RT-PCR, data are expressed as the mean \pm S.D. ( $n=3$ /group).
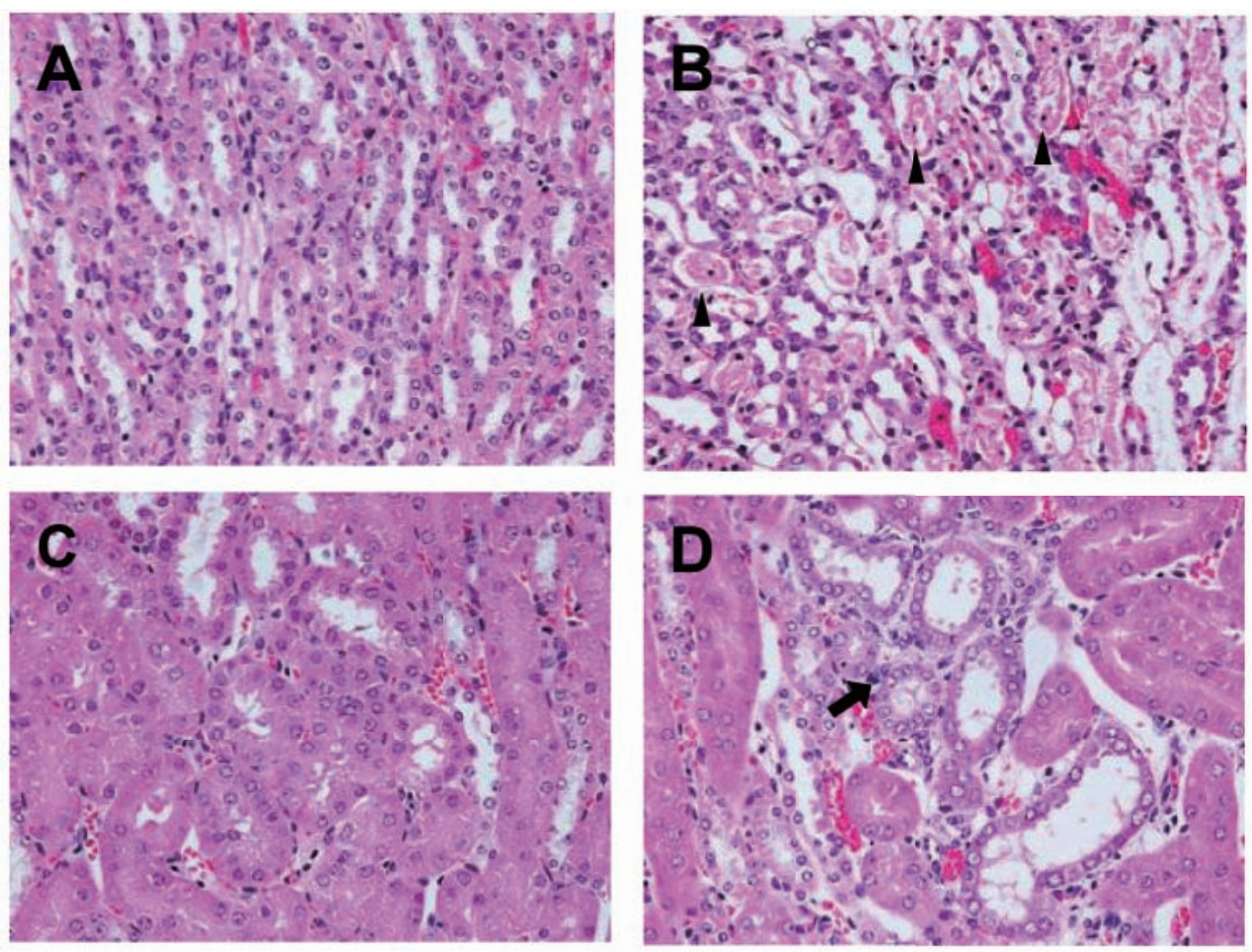

Fig. 2. ROC analysis of candidate biomarker genes. ROC analysis of gene expression data obtained from 24 nephrotoxicity negative and 26 nephrotoxicity positive individual samples. The curves shown were obtained by importing sensitivity and 1-specificity values. 
Nephrotoxicity biomarkers in mice
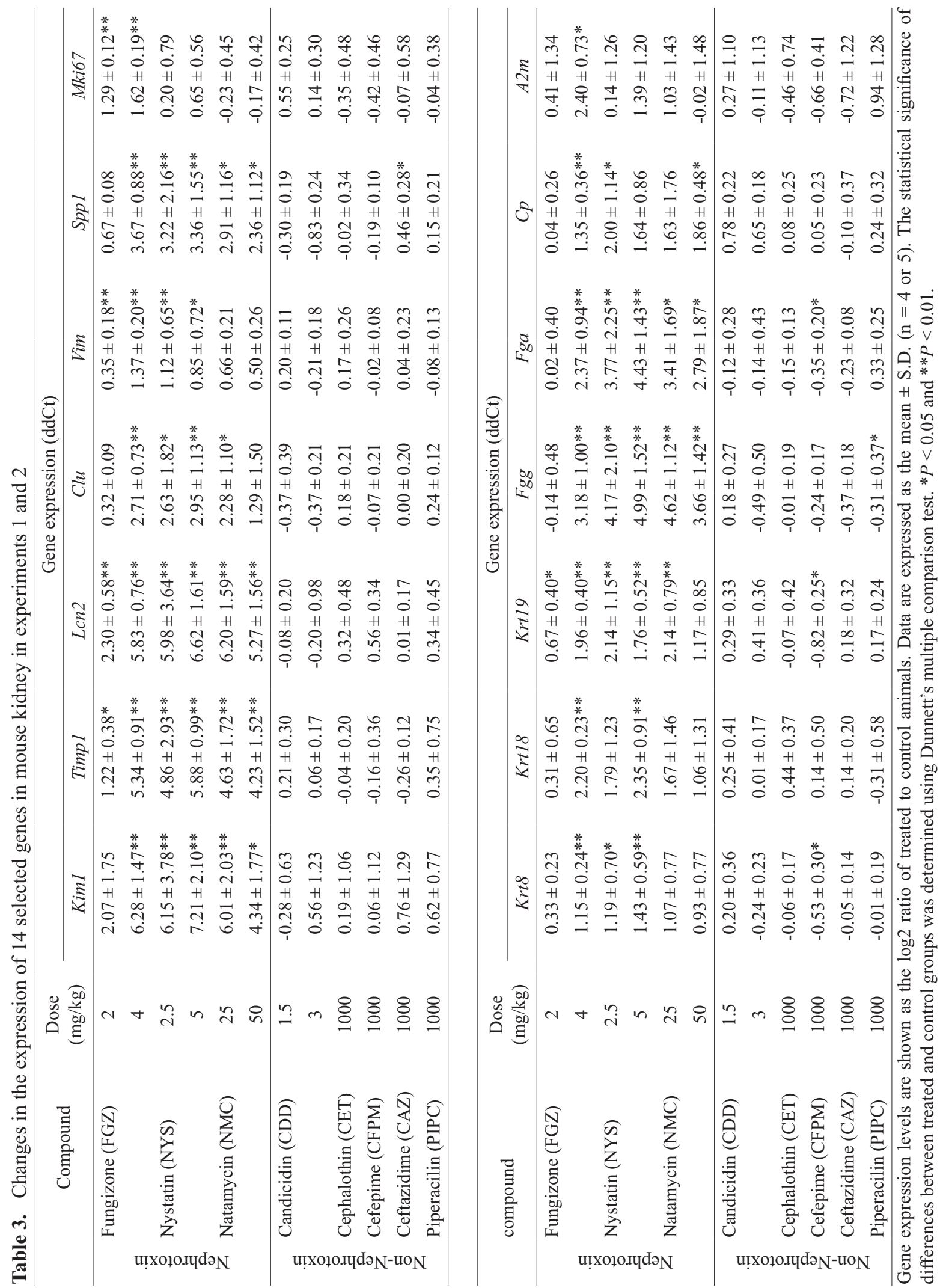

Vol. 37 No. 4 

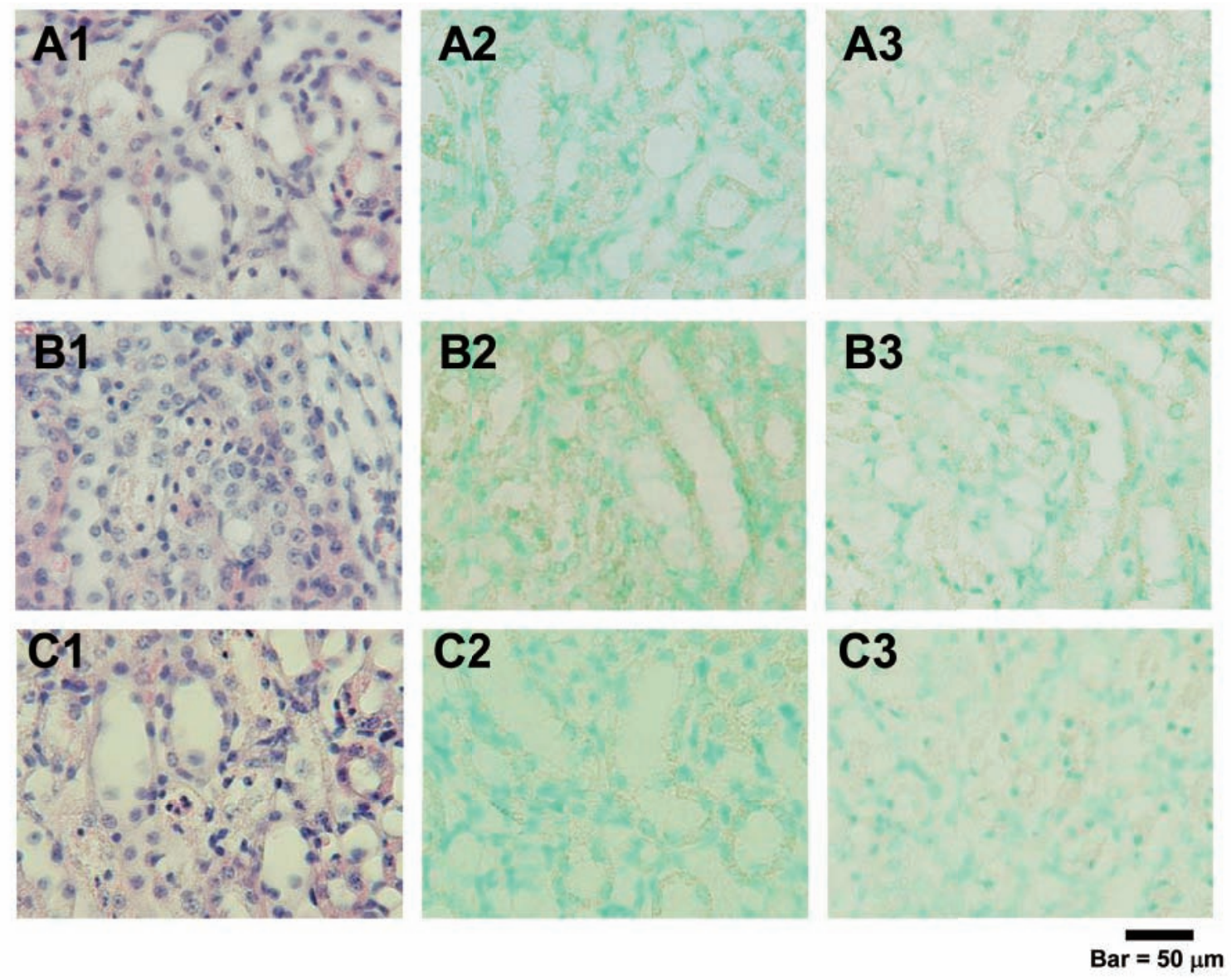

Fig. 3. In situ hybridization of Kim1, Lcn2, and Timp1 mRNA in the Fungizone-treated mouse kidney. Representative images of renal medulla of a mouse treated with $4 \mathrm{mg} / \mathrm{kg}$ of Fungizone in a single-dose experiment are shown (A1, B1, C1: H\&E staining). The positive staining is shown as diaminobenzidine deposits of dark-brownish color (nuclei: counterstained with methyl green). The weak to intense positive staining is observed with the antisense probes of Kim1 (A2), Lcn2 (B2), and Timp1 (C2) in the epithelial cells of the thin segment of Henle's loop compared to those of the sense probes (A3, B3, and C3, respectively). Magnification: $\times 200$.

reduced nephrotoxicity compared to AMB. Higher doses of L-AMB or AME are therefore needed for induction of nephrotoxicity. In our experimental condition, a dose of $50 \mathrm{mg} / \mathrm{kg}$ or more of L-AMB or AME were necessary to induce nephrotoxicity in mice and no nephrotoxicity was observed at $25 \mathrm{mg} / \mathrm{kg} \mathrm{L-AMB}$ (Table 1). In gene expression, Kim1, Lcn2, Timp1, and Spp1 were significantly upregulated in all dose groups treated with L-AMB and AME regardless of the presence or absence of phenotypic changes. Expression of Kiml was upregulated in the 25 $\mathrm{mg} / \mathrm{kg}$ AME-treated group, but not to a statistically significant degree. $K r t 8$ was significantly upregulated only in the 100 and $200 \mathrm{mg} / \mathrm{kg} \mathrm{L}$-AMB-treated groups (Table 4).

\section{External validation in repeated dose conditions}

In general, the potential toxicity of novel synthesized compounds is generally evaluated under repeated dose conditions. If biomarkers are to be useful in detecting signs of nephrotoxicity in nonclinical toxicology studies, sustained upregulation regardless of study conditions is required. A validation study was therefore conducted using mice administered a repeated dose of FGZ for 1 week. Following a daily dose of $2 \mathrm{mg} / \mathrm{kg} \mathrm{FGZ}$ for 1 week, the extent of upregulation was similar to that observed with the single dose of $2 \mathrm{mg} / \mathrm{kg}$. Although no significant upregulation was observed in this experiment among the five top-ranked genes identified by ROC analysis, $L c n 2$, Kim1, Timp1, and Spp1 did show some degree of upregulation following repeated dosing with FGZ for 1 week. 
Nephrotoxicity biomarkers in mice

Table 4. Changes in the expression of five selected genes in mouse kidney in experiments 3 and 4

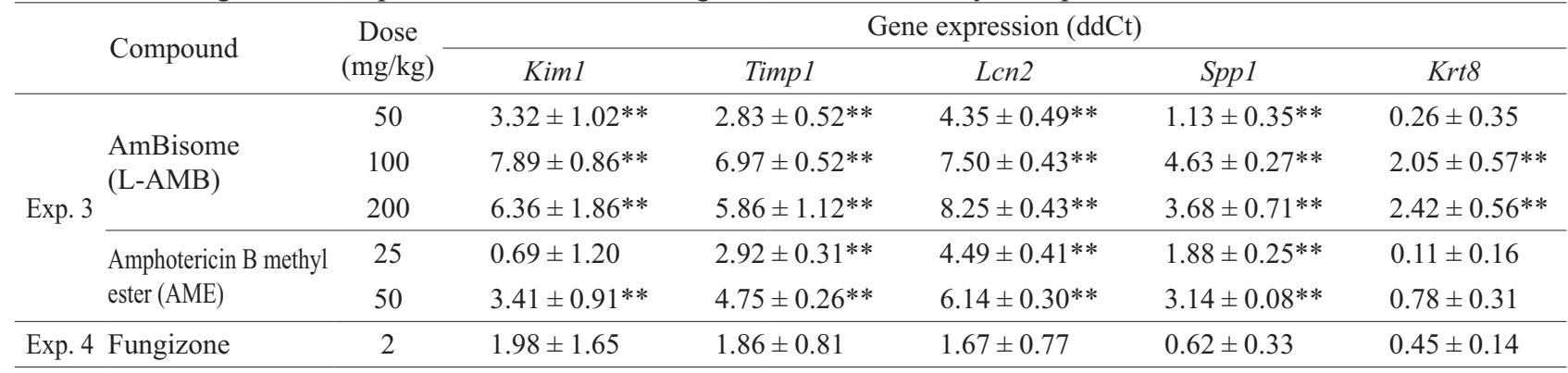

Gene expression levels are shown as the log2 ratio of treated to control animals. Data are expressed as the mean \pm S.D. ( $n=4$ or 5). The statistical significance of differences between treated and control groups was determined using Dunnett's multiple comparison test. $* P<0.05$ and $* * P<0.01$.

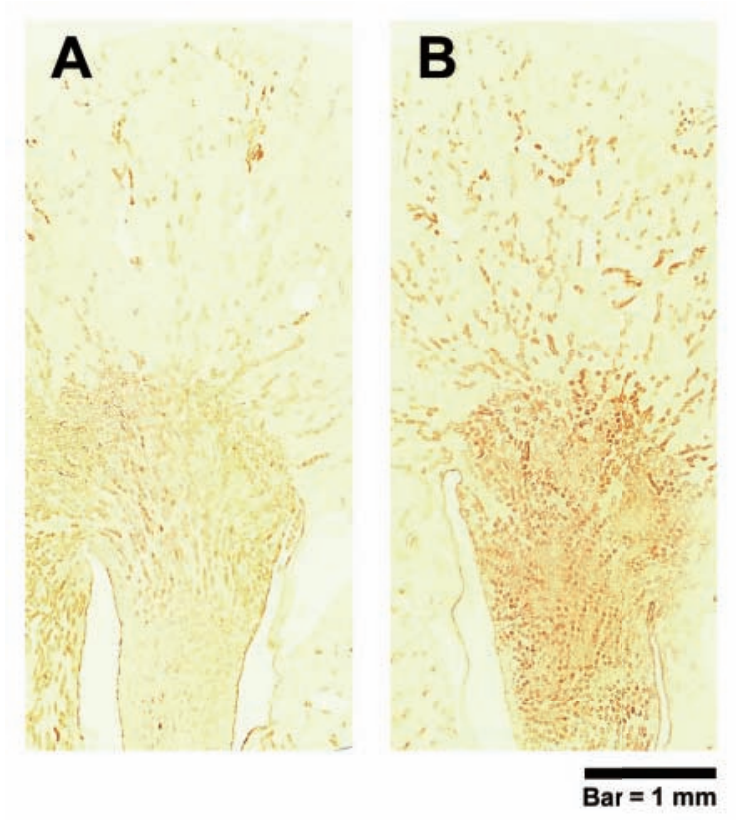

Fig. 4. Immunohistochemistry of osteopontin expression in the Fungizone-treated mouse kidney. Representative images of renal medulla of a mouse treated with vehicle alone (A) or $4 \mathrm{mg} / \mathrm{kg}$ of Fungizone (B) in a singledose experiment are shown. The positive staining is shown as diaminobenzidine deposits of dark-brownish color. In a mouse kidney treated with Fungizone, increased positive staining is observed in the epithelial cells of the thin segment of Henle's loop.

No clear upregulation was observed with Krt8 (Table 4).

\section{Localization of selected biomarkers in the nephron}

To investigate the mRNA or protein expression of selected biomarkers in the kidney, in situ hybridization or immunohistochemistry was performed in the FGZ-treated mouse kidneys. In the control kidneys, no or weak staining was detected with an antisense probe (data not shown). In contrast, weak to intense positive signals were detected with the antisense probes of Kim1, Lcn2, and Timp 1 in the epithelial cells of the thin segment of Henle's loop, which is the primary target of FGZ-induced nephrotoxicity (Fig. 3). In immunohistochemistry of osteopontin, extensive positive staining was observed in the whole kidney region, but intense staining was localized in the thin segment of Henle's loop (Fig. 4).

\section{DISCUSSION}

In the present study, we employed a toxicogenomic approach to identify translational biomarker genes in mice for use in predicting the nephrotoxicity of candidate drugs. In a previous study, we identified 92 nephrotoxicity biomarker genes and constructed a highly accurate classification model for the concurrent diagnosis of renal tubular injury in rats (Kondo et al., 2009). As a result, genes included in the previously described model were primarily involved in tissue remodeling, inflammatory responses, and cell growth. These categories of genes were considered to be common characteristics of gene expression changes reflecting renal tubular injuries. In this study, we first evaluated comprehensive changes in gene expression in mice in which acute nephrotoxicity was induced by AMB derivatives. The upregulated genes identified through microarray analysis of kidney tissue of FGZ-treated mice were also involved in tissue remodeling, inflammatory responses, and cell growth. In addition, these selected genes consisted of several genes that have been reported as nephrotoxicity biomarkers in rats. The results of our analysis therefore suggest that nephrotoxic biomarker genes in rats might be applicable also in mice. Among the genes highly upregulated in FGZ-treated mouse kidney, Kim1, Lcn2, Timp1, Spp1, Cp, Clu, Vim, 
A2m, Mki67, Fga, Fgg, Krt8, Krt18, and Krt19, were selected as candidate biomarkers because (i) there was the strong evidence supporting their usefulness as nephrotoxicity biomarkers in rats and other species (Alchi et al., 2005., Davis et al., 2004; Dieterich et al., 2009; Kharasch et al., 2006; Thukral et al., 2005; Wang et al., 2008) and (ii) these selected genes were considered to be biologically related to the gene categories, such as tissue remodeling, inflammatory responses, and cell growth. The usefulness of these genes as nephrotoxicity biomarkers in mice was evaluated further through expression profiling under several experimental conditions using real time RTPCR. As a result, Kim 1, Lcn2, Timp1, and Spp1 were the best predictors of nephrotoxicity, as determined by ROC analysis and further validation studies.

Kim1 (also known as Havcr1; hepatitis A virus cellular receptor 1) and Tim1 (T cell immunoglobulin mucin domains-1) encode type I transmembrane proteins. The expression of KIM1 in normal kidney can be hardly detected at the protein level. However, studies in ischemic and drug-induced acute nephrotoxicity models indicate that KIM1 protein is strongly induced in injured proximal tubular epithelial cells (Han et al., 2002; Ichimura et al., 1998, 2004; Prozialeck et al., 2007). It is presumed that KIM1 mediates the regeneration of tubular epithelial cells by assisting in the reconstitution of a continuous epithelial layer (Ichimura et al., 1998, 2008) and by regulating macrophage activation (Monney et al., 2002). The protein product of $L c n 2$ is known as neutrophil gelatinaseassociated lipocalin (NGAL). This protein is a member of the lipocalin family and binds to small hydrophobic molecules. Neutrophil gelatinase-associated lipocalin is produced by epithelial cells and inflammatory cells (Saiga et al., 2008; Vinuesa et al., 2008) and is involved in regulating immune responses, modulating cell growth and metabolism, transporting iron, and in prostaglandin synthesis (Shi et al., 2008). Timp1 is a glycoprotein expressed in several tissues that acts as an inhibitor of matrix metalloproteinases, a group of peptidases involved in degradation of the extracellular matrix. Timp 1 is produced by interstitial cells in the kidney and plays a major role in the inhibition of matrix degradation (Chromek et al., 2004; Hörstrup et al., 2002). Spp1 is a matrix glycoprotein containing an arginine-glycine-aspartate motif that binds to the integrin family of receptors and a soluble cytokine. It is highly expressed in damaged tissues and plays a role in wound healing, possibly by regulating inflammation and fibrosis (Butler, 1989; Wolak et al., 2009). Several studies have reported that these biomarker genes are more sensitive for detection of early kidney injury in rats and humans than other routinely used biomarkers, such as plasma creatinine and UN (Ichimura et al., 2004; Mishra et al., 2005; Nickolas et al., 2008; Sieber et al., 2009; Vaidya et al., 2006; Wang et al., 2008).

The usefulness of these genes was also evaluated in single- and repeated-dose experiments involving several AMB derivatives. In the single-dose study, the levels of Kim1, Lcn2, Timp 1, and Spp1 expression were clearly upregulated under all experimental conditions, with accompanying phenotypic changes in classical toxicology endpoints. The expression of these four genes was highly upregulated in high-dose AME- and low-dose L-AMBtreated mice that exhibited only very slight histopathological changes and no significant increases in creatinine or UN levels. Furthermore, Lcn2, Timp1, and Spp1 were clearly upregulated in low-dose AME-treated mice in which no significant biochemical or histopathological changes were observed. These results suggest that Kiml, Lcn 2, Timp1, and Spp1 are useful biomarkers for early detection of nephrotoxicity in mice, even in the absence of significant biochemical or histopathological changes.

Ideally, the expression of biomarker genes should be dose-dependent, and upregulation should be sustained following repeated dosing. In the FGZ-, NYS-, and AMEtreated groups, the expression of Kim1, Lcn2, Timp1, and Spp1 was clearly dose-dependent; however, there was no clear indication of dose-dependence in the expression of these genes in the NMC- and L-AMB-treated groups. In the NMC-treated group, the extent of histopathological injury was similar between the high- and low-dose groups, and no dose-dependent elevation was observed in the plasma UN level. We concluded that the acute toxic response in the NMC-treated mice had reached a plateau and that this was reflected by the gene expression profiles and classical toxicological findings. In contrast, L-AMBinduced nephrotoxicity was dose-dependent in our experiments whereas there was no clear indication of dosedependence in the expression of these genes between 100 and $200 \mathrm{mg} / \mathrm{kg}$ treated groups. It was suggested that upregulation of genes were saturated in the severely affected conditions. Taken together, there might be limited usefulness of genomic biomarkers in the ranking for severity of toxicity.

In the repeated-dose study involving FGZ, $2 \mathrm{mg} / \mathrm{kg} / \mathrm{day}$ was chosen as the experimental dose since $4 \mathrm{mg} / \mathrm{kg} /$ day was found to be intolerable after 1 week of repeated administration. Following 1 week of repeated dosing at $2 \mathrm{mg} / \mathrm{kg} /$ day of FGZ, proximal tubular necrosis was observed in addition to tubular necrosis in Henle's loop. Although regeneration was observed in the proximal tubule in the cortex after repeated dosing, the extent of medullary tubular necrosis was similar in mice receiv- 
Nephrotoxicity biomarkers in mice

ing single or repeated doses of $2 \mathrm{mg} / \mathrm{kg}$ of FGZ. As with the histopathological findings, the extent of upregulation of Kim1, Lcn2, Timp1, and Spp1 in mice receiving repeated doses was comparable to that in mice receiving a single dose. These results support our contention that $\operatorname{Kim} 1$, Lcn2, Timp1, and Spp1 would be useful nephrotoxic biomarkers in situations involving either single or repeated doses of potentially nephrotoxic compounds, although the data regarding repeated dosing are limited.

A variety of interesting histopathological changes were observed in our experiments, such as tubular necrosis in Henle's loop (with/without inflammatory cell infiltration), proximal tubular vacuolization, dilatation, and regeneration in the cortex. In situ hybridization and immunohistochemistry successfully confirmed the localization of expression in Henle's loop in the FGZ-induced nephrotoxicity. Our data strongly support a direct relationship between increased expression of these biomarkers and the tubular injuries in Henle's loop in FGZ-induced nephrotoxicity. However, it should be noted that Kim1, Lcn2, Timp1, and Spp 1 were commonly upregulated despite regional differences in the appearance of histopathological lesions in the various types of nephrotoxicity. Considered in light of the fact that whole kidneys were used for gene expression analysis in our experiments, we hypothesize that changes in the expression of Kim1, Lcn2, Timp1, and Sppl reflect various types of nephrotoxicity in each renal region as well as the nephrotoxicity in the Henle's loop. However, further study will be needed to better characterize the localization of each biomarker gene in the kidney, as only limited information is available regarding the distribution of gene expression in injured renal tissue.

Although we focused primarily on the four biomarker genes that were the best predictors of nephrotoxicity, there are several additional genes that may be useful in the detection of nephrotoxicity induced by the other classes of compounds. A recent study conducted in our laboratory suggested that changes in the expression of several cytoskeletal keratin genes might be useful indicators of damaged and/or regenerated renal tubules (Uehara et al., 2007), and in the present study, three keratin genes, Krt8, $\mathrm{Krt18}$, and Krt19 were found to be significantly upregulated in response to FGZ treatment. Among them, our study indicated that the expression profile of $K r t 8$, the gene encoding type II cytokeratin family protein (Hughson et al., 1993; Mertz et al., 2008; Moll et al., 1982), is different than that of Kim1, Lcn2, Timp1, and Spp1. In our experiments, $K r t 8$ was significantly upregulated in the middle- and high-dose L-AMB-treated groups, which also showed clear phenotypic changes in histopathology and clinical chemistry. However, Krt8 expression was not upregulated in the low-dose L-AMB- and AME-treated groups. These findings suggest that the sensitivity of Krt8 as a nephrotoxicity biomarker might be comparable to serum biomarkers such as creatinine and UN, and that therefore $K r t 8$ would be a useful diagnostic biomarker. Since it has been reported that different cytokeratins are expressed in injured and/or regenerated renal tubules (Uehara et al., 2007), further study will be required to characterize the distribution of these proteins in mouse kidney.

In the kidneys of FGZ-treated mice, GO analysis indicated that inflammatory responses was affected by FGZinduced changes in the expression of a number of genes, including Vim, Fga, and Fgg (Galichon and Hertig, 2011; Yang et al., 2007). Although the prediction accuracies of Krt19, Clu, Vim, Fga, and Fgg were inferior to those of the five top-ranked genes we ultimately selected as biomarkers, their AUC values were high, ranging from 0.901 to 0.947 . In particular, even though their performance as predictors of nephrotoxicity was inferior to the top-ranked genes, the fact that Fga and Fgg were highly upregulated in mice exposed to the nephrotoxic compounds used in our experiments suggests that their potential to serve as biomarkers in the other drug category be investigated further.

In conclusion, our results provide novel evidence that several nephrotoxicity biomarker genes identified in rats are translatable to mice, and that they are useful for early and sensitive detection of nephrotoxicity. Four genes in particular, Kim1, Lcn2, Timp1, and Spp1, were superior predictors of nephrotoxicity under conditions of both single and repeated dosing with nephrotoxic compounds. Although further large-scale studies will be needed to validate these genes as biomarkers for nephrotoxicity, our results indicate that they are applicable to the evaluation of nephrotoxicity in mice and that they will prove to be valuable in the development of safer drugs in the future.

\section{ACKNOWLEDGMENTS}

We thank Mr. Atsushi Ito for animal treatment and thank Ms. Takako Miyoshi and Ms. Yumi Asano for preparing the paraffin sections. We are also grateful to our toxicogenomics team members for their valuable suggestions.

\section{REFERENCES}

Alchi, B., Nishi, S., Kondo, D., Kaneko, Y., Matsuki, A., Imai, N., Ueno, M., Iguchi, S., Sakatsume, M., Narita, I., Yamamoto, T. and Gejyo, F., (2005): Osteopontin expression in acute renal allograft rejection. Kidney Int., 67, 886-896.

Butler, W.T. (1989): The nature and significance of osteopontin. 
Connect. Tissue Res, 23, 123-136.

Chromek, M., Tullus, K., Lundahl, J. and Brauner, A. (2004): Tissue inhibitor of metalloproteinase 1 activates normal human granulocytes, protects them from apoptosis, and blocks their transmigration during inflammation. Infect. Immun., 72, 82-88.

Clemons, K.V. and Stevens, D.A. (2004): Comparative Effecacies of Four Amphotericin B Formulations-Fungizone, Amphotec (Amphocil), AmBisome, and Abelcet-against Systemic Murine Aspergillosis. Antimicrob. Agents Chemother., 48, 1047-1050.

Cybulska, B., Gadomska, I., Mazerski, J., Borowski, J.G.E., Cheron, M. and Bolard, J. (2000): N-Methyl-N-D-fructosyl amphotericin B methyl ester (MF-AME), a novel antifungal agent of low toxicity: monomer/micelle control over selective toxicity. Acta. Biochim. Pol., 47, 121-131.

Davis, J.W.2nd., Goodsaid, F.M., Bral, C.M., Obert, L.A., Mandakas, G., Garner, C.E.2nd., Collins, N.D., Smith, R.J. and Rosenblum, I.Y. (2004): Quantitative gene expression analysis in a nonhuman primate model of antibiotic-induced nephrotoxicity. Toxicol. Appl. Pharmacol., 200, 16-26.

Deray, G. (2002): Amphotericin B nephrotoxicity. J. Antimicrob. Chemother., 49, Suppl. 1, 37-41.

Dieterle, F., Sistare, F., Goodsaid, F., Papaluca, M., Ozer, J.S., Webb, C.P., Baer, W., Senagore, A., Schipper, M.J., Vonderscher, J., Sultana, S., Gerhold, D.L., Phillips, J.A., Maurer, G., Carl, K., Laurie, D., Harpur, E., Sonee, M., Ennulat, D., Holder D., Andrews-Cleavenger, D., Gu, Y.Z., Thompson, K.L., Goering, P.L., Vidal, J.M., Abadie, E., Maciulaitis, R., JacobsonKram, D., Defelice, A.F., Hausner, E.A., Blank, M., Thompson, A., Harlow, P., Throckmorton, D., Xiao, S., Xu, N., Taylor, W., Vamvakas, S., Flamion, B., Lima, B.S., Kasper, P., Pasanen, M., Prasad, K., Troth, S., Bounous, D., Robinson-Gravatt, D., Betton, G., Davis, M.A., Akunda, J., McDuffie, J.E., Suter, L., Obert, L., Guffroy, M., Pinches, M., Jayadev, S., Blomme, E.A., Beushausen, S.A., Barlow, V.G., Collins, N., Waring, J., Honor, D., Snook, S., Lee, J., Rossi, P., Walker, E. and Mattes, W. (2010): Renal biomarker qualification submission: a dialog between the FDA-EMEA and Predictive Safety Testing Consortium. Nat. Biotechnol., 28, 455-462.

Dieterich, C., Puey, A., Lin, S., Swezey, R., Furimsky, A., Fairchild, D., Mirsalis, J.C. and Ng, H.H. (2009): Gene expression analysis reveals new possible mechanisms of vancomycin-induced nephrotoxicity and identifies gene markers candidates. Toxicol. Sci., 107, 258-269.

Dupont, B. (2002): Overview of the lipid formulations of amphotericin B. J. Antimicrob. Chemother., 49, Suppl. S1, 31-36.

Galichon, P. and Hertig, A. (2011): Epithelial to mesenchymal transition as a biomarker in renal fibrosis: are we ready for the bedside? Fibrogenesis Tissue Repair., 6, 4-11.

Grzybowska, J., Sowiński, P., Gumieniak, J., Zieniawa, T. and Borowski, E. (1997): N-methyl-N-D-fructopyranosylamphotericin B methyl ester, new amphotericin B derivative of low toxicity. J. Antibiot., 50, 709-811.

Guengerich, F.P. and MacDonald, J.S. (2007): Applying mechanisms of chemical toxicity to predict drug safety. Chem. Res. Toxicol., 20, 344-369.

Han, W.K., Bailly, V., Abichandani, R., Thadhani, R. and Bonventre, J.V. (2002): Kidney injury molecule-1 (KIM-1): a novel biomarker for human renal proximal tubule injury. Kidney Int., 62, 237 244.

Harrill, A.H., Ross, P.K., Gatti, D.M., Threadgill, D.W. and Rusyn, I. (2009): Population-based discovery of toxicogenomics biomarkers for hepatotoxicity using a laboratory strain diversity panel. Toxicol. Sci., 110, 235-243.

Hayes, K.R. and Bradfield, C.A. (2005): Advances in toxicogenomics. Chem. Res. Toxicol., 18, 403-414.

Heinloth, A.N., Irwin, R.D., Boorman, G.A., Nettesheim, P., Fannin, R.D., Sieber, S.O., Snell, M.L., Tucker, C.J., Li, L., Travlos, G.S., Vansant, G., Blackshear, P.E., Tennant, R.W., Cunningham, M.L. and Paules, R.S. (2004): Gene expression profiling of rat livers reveals indicators of potential adverse effects. Toxicol. Sci., 80, 193-202.

Hirode, M., Omura, K., Kiyosawa, N., Uehara, T., Shimuzu, T., Ono, A., Miyagishima, T., Nagao, T., Ohno, Y. and Urushidani, T. (2009) Gene expression profiling in rat liver treated with various hepatotoxic-compounds inducing coagulopathy. J. Toxicol. Sci., 34, 281-293.

Hörstrup, J.H., Gehrmann, M., Schneider, B., Plöger, A., Froese, P., Schirop, T., Kampf, D., Frei, U., Neumann, R. and Eckardt, K.U. (2002): Elevation of serum and urine levels of TIMP-1 and tenascin in patients with renal disease. Nephrol. Dial. Transplant. 17, 1005-1013.

Huang, Q., Dunn, R.T.2nd., Jayadev, S., DiSorbo, O., Pack, F.D., Farr, S.B., Stoll, R.E. and Blanchard, K.T., (2001): Assessment of cisplatin-induced nephrotoxicity by microarray technology. Toxicol. Sci., 6, 196-207.

Hughson, M., Johnson, L., Silva, F. and Kovacs, G.., (1993): Nonpapillary and papillary renal cell carcinoma: a cytogenetic and phenotypic study. Mod. Pathol., 6, 449-456.

Ichimura, T., Asseldonk, E.J., Humphreys, B.D., Gunaratnam, L., Duffield, J.S. and Bonventre, J.V. (2008): Kidney injury molecule-1 is a phosphatidylserine receptor that confers a phagocytic phenotype on epithelial cells. J. Clin. Invest., 118, 1657-1668.

Ichimura, T., Bonventre, J.V., Bailly, V., Wei, H., Hession, C.A. and Cate, R.L. (1998): Kidney injury molecule-1 (KIM-1), a putative epithelial cell adhesion molecule containing a novel immunoglobulin domain, is up-regulated in renal cells after injury. J. Biol. Chem., 273, 4135-4142.

Ichimura, T., Hung, C.C., Yang, S.A., Stevens, J.L. and Bonventre, J.V. (2004): Kidney injury molecule-1: a tissue and urinary biomarker for nephrotoxicant-induced renal injury. Am. J. Physiol. Renal. Physiol., 286, F552-563.

Keim, G.R.Jr., Poutsiaka, J.W., Kirpan, J. and Keysser, C.H. (1973): Amphotericin B Methyl Ester Hydrochloride and Amphotericin B: Comparative Acute Toxicity. Science, 179, 584-585.

Kharasch, K.D., Schroeder, J.L., Bammler, T., Beyer, R. and Srinouanprachanh, S. (2006): Gene expression profiling of nephrotoxicity from the sevoflurane degradation product fluoromethyl-2,2-difluoro-1-(trifluoromethyl)vinyl ether ("Compound A") in rats. Toxicol. Sci., 90, 419-431.

Kiyosawa, N., Uehara, T., Gao, W., Omura, K., Hirode, M., Shimizu, T., Mizukawa, Y., Ono, A., Miyagishima, T., Nagao, T. and Urushidani, T. (2007): Identification of glutathione depletionresponsive genes using phorone-treated rat liver. J. Toxicol. Sci. 32, 469-486.

Kondo, C., Minowa, Y., Uehara, T., Okuno, Y., Nakatsu, N., Ono, A., Maruyama, T., Kato, I., Yamate, J., Yamada, H., Ohno, Y. and Urushidani, T. (2009): Identification of genomic biomarkers for concurrent diagnosis of drug-induced renal tubular injury using a large-scale toxicogenomics database. Toxicology, 265, 15-26.

Leenders, A.C., Daenen, S., Jansen, R.L., Hop, W.C., Lowenberg, B., Wijermans, P.W., Cornelissen, J., Herbrecht, R., van der Lelie, H., Hoogsteden, H.C., Verbrugh, H.A. and de Marie, S. (1998): Liposomal amphotericin B compared with amphoter- 
Nephrotoxicity biomarkers in mice

icin B deoxycholate in the treatment of documented and suspected neutropenia-associated invasive fungal infections. Br. J. Haematol., 103, 205-212.

Low, Y., Uehara, T., Minowa, Y., Yamada, H., Ohno, Y., Urushidani, T., Sedykh, A., Muratov, E., Kuz'min, V., Fourches, D., Zhu, H., Rusyn, I. and Tropsha, A., (2011): Predicting drug-induced hepatotoxicity using QSAR and toxicogenomics approaches. Chem. Res. Toxicol., 24, 1251-1262.

Luhe, A., Hildebrand, H., Bach, U., Dingermann, T. and Ahr, H.J. (2003): A new approach to studying ochratoxin A (OTA)-induced nephrotoxicity: expression profiling in vivo and in vitro employing cDNA microarrays. Toxicol. Sci., 73, 315-328.

Mertz, K.D., Demichelis, F., Sboner, A., Hirsch, M.S., Dal, Cin. P., Struckmann, K., Storz, M., Scherrer, S., Schmid, D.M., Strebel, R.T., Probst-Hensch, N.M., Gerstein, M., Moch, H. and Rubin, M.A. (2008): Association of cytokeratin 7 and 19 expression with genomic stability and favorable prognosis in clear cell renal cell cancer. Int. J. Cancer, 123, 569-576.

Mishra, J., Dent, C., Tarabishi, R., Mitsnefes, M.M., Ma, Q., Kelly, C., Ruff, S.M., Zahedi, K., Shao, M., Bean, J., Mori, K., Barasch, J. and Devarajan, P. (2005): Neutrophil gelatinase-associated lipocalin (NGAL) as a biomarker for acute renal injury after cardiac surgery. Lancet, 365, 1231-1238.

Moll, R., Franke, W.W., Schiller, D.L., Geiger, B. and Krepler, R. (1982): The catalog of human cytokeratins: patterns of expression in normal epithelia, tumors and cultured cells. Cell, 31, 11-24.

Monney, L., Sabatos, C.A., Gaglia, J.L., Ryu, A., Waldner, H., Chernova, T., Manning, S., Greenfield, E.A., Coyle, A.J., Sobel, R.A., Freeman, G.J. and Kuchroo, V.K. (2002): Th1-specific cell surface protein Tim-3 regulates macrophage activation and severity of an autoimmune disease. Nature, 415, 536-541.

Mori, Y., Kondo, C., Tonomura, Y., Torii, M. and Uehara, T. (2010): Identification of potential genomic biomarkers for early detection of chemically induced cardiotoxicity in rats. Toxicology, 271, 36-44.

Nickolas, T.L., O’Rourke, M.J., Yang, J., Sise, M.E., Canetta, P.A., Barasch, N., Buchen, C., Khan, F., Mori, K. and Giglio, J. (2008): Sensitivity and specificity of a single emergency department measurement of urinary neutrophil gelatinase-associated lipocalin for diagnosing acute kidney injury. Ann. Intern. Med. 148, 810-819.

Ozaki, N., Matheis, K.A., Gamber, M., Feidl, T., Nolte, T., Kalkuhl, A. and Deschl, U. (2010): Identification of genes involved in gentamicin-induced nephrotoxicity in rats--a toxicogenomic investigation. Exp. Toxicol. Pathol., 62, 555-566.

Paules, R. (2003): Phenotypic anchoring: linking cause and effect. Environ. Health Perspect., 111, A338-339.

Prozialeck, W.C., Vaidya, V.S., Liu, J., Waalkes, M.P., Edwards, J.R., Lamar, P.C., Bernard, A.M., Dumont, X. and Bonventre, J.V. (2007): Kidney injury molecule-1 is an early biomarker of cadmium nephrotoxicity. Kidney Int., 72, 985-993.

Reuhl, K.R., Vapiwala, M., Ryzlak, M.T. and Schaffner, C.P. (1993): Comparative neurotoxicities of amphotericin B and its monomethyl ester derivative in rats. Antimicrob. Agents Chemother., 37, 419-428.

Saiga, H., Nishimura, J., Kuwata, H., Okuyama, M., Matsumoto, S., Sato, S., Matsumoto, M., Akira, S., Yoshikai, Y., Honda, K., Yamamoto, M., Takeda, K. (2008): Lipocalin 2-Dependent Inhibition of Mycobacterial Growth in Alveolar Epithelium. J.
Immunol., 181, 8521-8527.

Shi, H., Gu, Y., Yang, J., Xu, L., Mi, W. and Yu, W. (2008): Lipocalin 2 promotes lung metastasis of murine breast cancer cells. J. Exp. Clin. Cancer Res., 27, 83.

Sieber, M., Hoffmann, D., Adler, M., Vaidya, V.S., Clement, M., Bonventre, J.V., Zidek, N., Rached, E., Amberg, A., Callanan, J.J., Dekant, W. and Mally, A. (2009): Comparative analysis of novel noninvasive renal biomarkers and metabonomic changes in a rat model of gentamicin nephrotoxicity. Toxicol. Sci., 109, 336-349.

Thukral, S.K., Nordone, P.J., Hu, R., Sullivan, L., Galambos, E., Fitzpatrick, V.D., Healy, L., Bass, M.B., Cosenza, M.E. and Afshari, C.A. (2005): Prediction of nephrotoxicant action and identification of candidate toxicity-related biomarkers. Toxicol. Pathol., 33, 343-355.

Tonomura, Y., Yamamoto, E., Kondo, C., Itoh, A., Tsuchiya, N., Uehara, T. and Baba, T. (2009): Amphotericin B-induced nephrotoxicity: characterization of blood and urinary biochemistry and renal morphology in mice. Hum. Exp. Toxicol., 28, 293-300.

Uehara, T., Hirode, M., Ono, A., Kiyosawa, N., Omura, K., Shimizu, T., Mizukawa, Y., Miyagishima, T., Nagao, T. and Urushidani, T. (2008): A toxicogenomics approach for early assessment of potential non-genotoxic hepatocarcinogenicity of chemicals in rats. Toxicology, 250, 15-26.

Uehara, T., Kondo, C., Yamate, J., Torii, M. and Maruyama, T. (2011): A toxicogenomic approach for identifying biomarkers for myelosuppressive anemia in rats. Toxicology, 282, 139-145.

Uehara, T., Minowa, Y., Morikawa, Y., Kondo, C., Maruyama, T., Kato, I., Nakatsu, N., Igarashi, Y., Ono, A., Hayashi, H., Mitsumori, K., Yamada, H., Ohno, Y. and Urushidani, T., (2011): Prediction model of potential hepatocarcinogenicity of rat hepatocarcinogens using a large-scale toxicogenomics database. Toxicol. Appl. Pharmacol., 255, 297-306.

Uehara, T., Miyoshi, T., Tsuchiya, N., Masuno, K., Okada, M., Inoue, S., Torii, M., Yamate, J. and Maruyama, T. (2007): Comparative analysis of gene expression between renal cortex and papilla in nedaplatin-induced nephrotoxicity in rats. Hum. Exp. Toxicol., 26, 767-780.

Vaidya, V.S., Ramirez, V., Ichimura, T., Bobadilla, N.A. and Bonventre, J.V. (2006): Urinary kidney injury molecule-1: a sensitive quantitative biomarker for early detection of kidney tubular injury. Am. J. Physiol. Renal. Physiol., 290, 517-529.

Vinuesa, E., Sola, A., Jung, M., Alfaro, V. and Hotter, G. (2008): Lipocalin-2-induced renal regeneration depends on cytokines. Am. J. Physiol. Renal Physiol., 295, 1554-1562.

Wang, E.J., Snyder, R.D., Fielden, M.R., Smith, R.J. and Gu, Y.Z. (2008): Validation of putative genomic biomarkers of nephrotoxicity in rats. Toxicology, 246, 91-100.

Wingard, J.R., White, M.H., Anaissie, E., Raffalli, J., Goodman, J. and Arrieta, A. (2000): A randomized, double-blind comparative trial evaluating the safety of liposomal amphotericin B versus amphotericin B lipid complex in the empirical treatment of febrile neutropenia. Clin. Infect. Dis., 31, 1155-1163.

Wolak, T., Kim, H., Ren, Y., Kim, J., Vaziri, N.D. and Nicholas, S.B. (2009): Osteopontin modulates angiotensin IIinduced inflammation, oxidative stress, and fibrosis of the kidney. Kidney Int., 76, 32-43.

Yang, A., Trajkovic, D., Illanes, O. and Ramiro-Ibáñez, F., (2007): Clinicopathological and tissue indicators of para-aminophenol nephrotoxicity in sprague-dawley rats. Toxicol. Pathol., 35, 521532. 